\title{
Construction of non-polar mutants in Haemophilus influenzae using FLP recombinase technology Erin Tracy ${ }^{1}$, Fang Ye ${ }^{1}$, Beth D Baker ${ }^{1}$ and Robert S Munson Jr*1,2
} Address: ${ }^{1}$ Center for Microbial Pathogenesis in The Research Institute at Nationwide Children's Hospital, Columbus, OH, USA and ${ }^{2}$ The Center
for Microbial Interface Biology and Department of Pediatrics, The Ohio State University, Columbus, OH, USA

Email: Erin Tracy - Erin.Tracy@nationwidechildrens.org; Fang Ye - Fang.Ye@nationwidechildrens.org; Beth D Baker - Beth.Baker@nationwidechildrens.org; Robert S Munson* - Munson.10@osu.edu

* Corresponding author

Published: II November 2008

BMC Molecular Biology 2008, 9:101 doi:10.1 186/1471-2199-9-101
Received: 30 May 2008

Accepted: II November 2008

This article is available from: http://www.biomedcentral.com/I47I-2199/9/10।

(C) 2008 Tracy et al; licensee BioMed Central Ltd.

This is an Open Access article distributed under the terms of the Creative Commons Attribution License (http://creativecommons.org/licenses/by/2.0), which permits unrestricted use, distribution, and reproduction in any medium, provided the original work is properly cited.

\begin{abstract}
Background: Nontypeable Haemophilus influenzae (NTHi) is a gram-negative bacterium that causes otitis media in children as well as other infections of the upper and lower respiratory tract in children and adults. We are employing genetic strategies to identify and characterize virulence determinants in NTHi. NTHi is naturally competent for transformation and thus construction of most mutants by common methodologies is relatively straightforward. However, new methodology was required in order to construct unmarked non-polar mutations in poorly expressed genes whose products are required for transformation. We have adapted the lambda $\mathrm{red} /$ FLP-recombinase-mediated strategy used in $E$. coli for use in NTHi.
\end{abstract}

Results: A cassette containing a spectinomycin resistance gene and an $r p s L$ gene flanked by FRT sites was constructed. A PCR amplicon containing 50 base pairs of DNA homologous to the $5^{\prime}$ and 3 ' ends of the gene to be disrupted and the cassette was generated, then recombineered into the target NTHi gene, cloned on a plasmid, using the lambda recombination proteins expressed in $E$. coli DY380. Thus, the gene of interest was replaced by the cassette. The construct was then transformed into a streptomycin resistant NTHi strain and mutants were selected on spectinomycin-containing growth media. A plasmid derived from pLS88 with a temperature sensitive replicon expressing the FLP recombinase gene under the control of the tet operator/ repressor was constructed. This plasmid was electroporated into the NTHi mutant at the permissive temperature and FLP expression was induced using anhydrotetracycline. The recombinase recognizes the FRT sites and eliminates the antibiotic cassette by site-specific recombination, creating the unmarked non-polar mutation. The plasmid is cured by growth of cells at the restrictive temperature.

Conclusion: The products of the genes in the NTHi pilABCD operon are required for type IV pilus biogenesis and have a role in transformation. We demonstrated the utility of our methodology by the construction of a non-polar pilA mutation in NTHi strain 2019 and complementation of the mutation with a plasmid containing the pilA gene. Utilization of this approach allowed us to readily generate unmarked non-polar mutations in NTHi genes. 


\section{Background}

Nontypeable Haemophilus influenzae (NTHi) is a gramnegative bacterium, which is a major cause of otitis media $[1,2]$. The organism also causes pneumonia and other respiratory tract diseases in humans $[1,2]$. Type IV pili (Tfp) mediate adherence, twitching motility, and play a role in transformation (reviewed by Craig et al [3]). We previously demonstrated that NTHi produce Tfp under defined environmental conditions. These Tfp are responsible for twitching motility, Tfp-mediated adherence and contribute to biofilm development [4-6]. The products of the pil$A B C D$ gene cluster play a role in Tfp biogenesis $[4,7,8]$. The pilA gene is predicted to encode the major pilin subunit. The PilB protein is homologous to hexameric secretion ATPases and the PilC protein has homology to inner membrane proteins required for Tfp pilus assembly in other organisms. PilD is predicted to be the prepilin peptidase. These genes are in an operon, which necessitates the construction of non-polar mutants in order to carefully define the role of each gene product.

In NTHi, non-polar mutants have been constructed using the non-polar kanamycin resistance cassette designed by Menard et al [9], see for example Mason et al [10]. This kanamycin resistance gene is promoter-less; thus, transcription is driven from the promoter of the operon. The level of transcription must therefore be at a level sufficient to confer a kanamycin-resistant phenotype to the mutant under normal growth conditions. Alternatively, a nonpolar mutant can be constructed in two steps. First, a mutant is constructed using standard methodologies [11] in which a gene has been interrupted with a cassette containing both a selectable and counter-selectable marker. Then, DNA containing an in-frame deletion of the gene of interest together with flanking chromosomal DNA 5 ' and $3^{\prime}$ of the deleted gene is transformed into the mutant. Mutants containing the in-frame deletion are isolated by selection against the counter-selectable marker. Neither of these methodologies is suitable for use with genes whose products are required for transformation since the genes are poorly expressed under normal growth conditions and mutants deficient in the expression of these genes cannot be transformed. We thus adapted the methodologies employed by Wanner and coworkers $[12,13]$ to construct non-polar mutations in NTHi.

\section{Results and discussion}

Construction of a non-polar mutant in the NTHi pilA gene

Mutations have been engineered into the E. coli chromosome using the lambda phage recombinase to catalyze the site-specific insertion of a PCR amplicon containing $50 \mathrm{bp}$ homology arms and a cassette flanked by FRT (FLP recombinase target) sites, replacing the gene of interest $[12,13]$. Given the restriction barriers present in NTHi strains, it was necessary to perform the insertional inactivation of the NTHi genes of interest by cloning the gene together with flanking sequences onto a plasmid, then insertionally inactivating the gene in E. coli before moving the mutation into NTHi using the natural transformation system [11]. E. coli strain DY380 has previously been used for engineering plasmids using the products of the phage lambda recombinase genes [14]. This strain is lysogenized with a defective lambda phage that expresses the recombinase genes under the control of the temperature sensitive $\lambda$ cI857 repressor and thus is a suitable host for recombineering [15]. In order to construct a pilA mutation in NTHi, the pil gene cluster was first amplified from NTHi strain 2019, then cloned into pGEM-T Easy and transformed into E. coli strain DY380 to form strain DY380(pRSM2855).

The plasmid pKD13 contains the kanamycin resistance gene from Tn5 flanked by FRT sites recognized by the FLP recombinase [13]. We modified pKD13 so that it contained a spectinomycin resistance gene; in NTHi, spectinomycin provides a strong selectable marker with little background. The normal allele of an rpsL gene from Neisseria gonorrhoeae (designated $r p s L_{\mathrm{Ng}}$ ) was also added to the construct to provide a counter selectable marker [16]. This plasmid was designated pRSM2832. Employing pRSM2832 as a template, a PCR amplicon was generated using the strategy of Baba et al [12]. The 5' primer was designed to include $50 \mathrm{nt} 5^{\prime}$ to and including the ATG start codon of the pilA gene. The 3' primer was designed to contain the complement of the last $21 \mathrm{nt}$ including the stop codon of the pilA gene. Both primers contained regions homologous to the cassette containing the spectinomycin resistance gene and the $r p s L_{\mathrm{Ng}}$ gene (Figure 1). The amplicon (Figure 2A) was electroporated into E. coli strain DY380(pRSM2855) after heat shock and spectinomycinresistant clones were isolated. A plasmid containing the anticipated insertion/deletion mutation in the pilA gene was saved as pRSM2857 (Figure 2C).

NTHi strain 2019 is a well-characterized isolate from a patient with chronic bronchitis [17-19]. The pRSM 2857 insert was separated from the plasmid backbone by digestion with NcoI and NsiI, then transformed into a streptomycin-resistant derivative of NTHi strain 2019, designated NTHi strain 2019 rpsL, using the MIV methodology [11]. A strain containing the anticipated insertion/ deletion mutation in the pilA gene was saved as NTHi strain $2019 r p s L \Delta p i l A:: s p e c-r p s L_{N g}$. The next step in the construction was the removal of the cassette, which is flanked by FRT sites, by expression of the FLP recombinase.

We constructed a temperature sensitive derivative of pLS88, a plasmid that replicates in NTHi and cloned the FLP recombinase gene into this construct under control of 

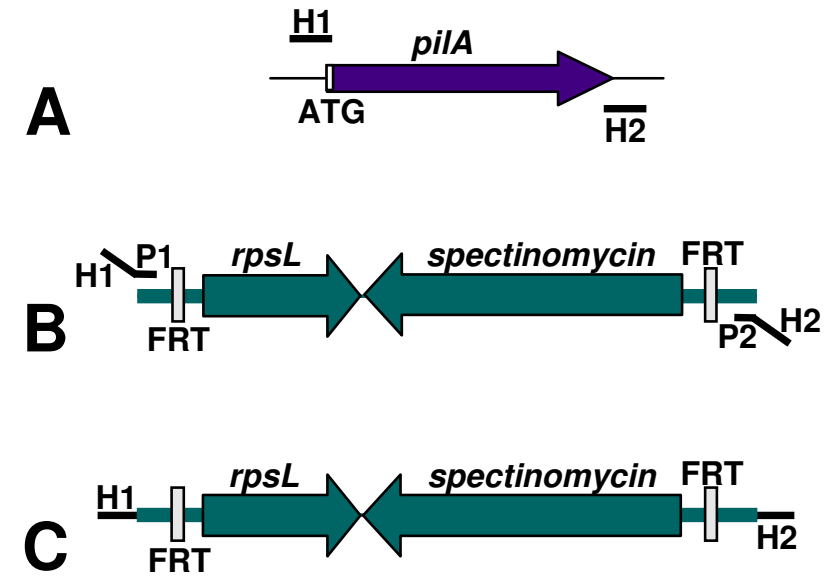

Figure I

Generation of a PCR amplicon for insertion/deletion mutagenesis of the pilA gene. In Panel $A$, the pilA gene from NTHi strain 2019 is shown. Homology arm I (HI) contains 50 base pairs of DNA 5 ' to and including the ATG start codon of pilA. Homology arm $2(\mathrm{H} 2)$ contains the complement of the last 21 base pairs of the pilA gene and 29 base pairs immediately downstream of the pilA gene. In Panel $B$, the template region of PRSM2832 is shown. Primer HIPI contains the sequence from $\mathrm{HI}$ and 20 base pairs of DNA homologous to the $5^{\prime}$ end of the cassette (PI). Primer H2P2 contains the sequence from $\mathrm{H} 2$ and 20 base pairs of DNA homologous to the $3^{\prime}$ end of the cassette. PCR amplification of pRSM2832 with primers HIPI and H2P2 (primers 5 and 6) yielded the product shown in Panel $\mathrm{C}$.

the tet operator/repressor (Figure 3). This plasmid, designated pRSM2947, was electroporated into NTHi strain $2019 r p s L \Delta$ ilA::spec-rps $L_{\mathrm{Ng}}$ and kanamycin resistant clones were isolated. One clone was saved as NTHi strain $2019 r p s L \Delta p i l A:: s p e c-r p s L_{\mathrm{Ng}}$ (pRSM2947). Expression of the FLP recombinase was induced in this strain, then clones were isolated at $37^{\circ} \mathrm{C}$ on streptomycin-containing medium. One streptomycin-resistant clone was saved as NTHi strain 2019 rpsL $\Delta$ pilA for further characterization. The pil region in the mutant is represented in Figure 2D.

\section{The NTHi strain 2019 rpsLApilA mutant was not} transformable; the phenotype was complemented by the pilA gene

The product of the genes in the pil gene cluster is required for transformation using the MIV methodology [4]. Transformability of the $\Delta$ pilA mutant was tested using a modification of the MIV methodology [4]. In order to generate a DNA substrate for transformation, we cloned, then insertionally inactivated, the $H$. influenzae strain $\mathrm{Rd}$ cya gene with a non-polar kanamycin cassette to form pRSM2948 (data not shown). Plasmids were digested with NotI. The linear DNA fragment containing the inter- rupted cya gene was transformed into the NTHi strain 2019 rpsLApilA and strain 2019 rpsL using the modified MIV methodology. Transformants were selected on chocolate agar containing kanamycin. Transformation efficiency (number of transformants/ $\mu$ g of DNA) is shown in Table 1 . Approximately $5 \times 10^{5}$ transformants/ $\mu$ g of DNA was obtained with strain 2019 rpsL, while transformants were not detected with the mutant under these conditions. We cloned the pilA gene into a shuttle vector forming pRSM2848 and electroporated the construct into NTHi strain 2019 rpsL $\Delta$ pilA. We then tested the transformability of the complemented strain using the interrupted cya gene as described above. Approximately $1.5 \times 10^{5}$ transformants/ $\mu$ g of DNA was obtained with the complemented strain (Table 1).

Although the putative functions of the pilB, pilC and pilD genes make it likely that the products of these genes are required for transformation, we demonstrated that a polar mutation in the pilA gene could not be complemented with plasmid pRSM2848, the plasmid expressing the pilA

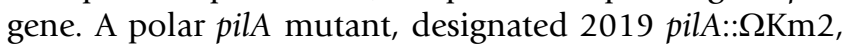
was constructed by insertion of the $\Omega \mathrm{Km} 2$ cassette into the pilA gene as described [4]. As anticipated, this mutant is not transformable and the mutation could not be complemented with the cloned pilA gene (Table 1).

\section{Conclusion}

We have developed a new methodology for the construction of mutants in NTHi. This methodology was developed to overcome technical issues related to the construction of non-polar mutants in poorly expressed genes whose products are required for transformation. However, the method is straightforward and robust. We have successfully constructed over 20 mutants using this method and now construct all $H$. influenzae mutants in our laboratory using this method. The methodology should also be applicable to other naturally transformable members of the Pasteurellaceae family that support the replication of pLS88 derivatives.

\section{Methods \\ Bacterial strains, plasmids and growth conditions}

NTHi strain 2019 is a well characterized strain from a patient with chronic bronchitis [17-19]. NTHi strain 2019 rpsL was constructed by Apicella and coworkers. This strain contains a mutation resulting in a K43R modification in RpsL; the strain is resistant to $1 \mathrm{mg}$ of streptomy$\mathrm{cin} / \mathrm{ml}$. Both strains were kindly provided by Dr. Michael Apicella. NTHi strains were grown on chocolate agar or in Brain Heart Infusion broth supplemented with $2 \mu \mathrm{g}$ of $\mathrm{NAD} / \mathrm{ml}$ and $2 \mu \mathrm{g}$ of heme/ml (sBHI). Growth media were supplemented with spectinomycin, kanamycin, chloramphenicol or streptomycin at $200 \mu \mathrm{g} / \mathrm{ml}, 20 \mu \mathrm{g} / \mathrm{ml}$, $1 \mu \mathrm{g} / \mathrm{ml}$ or $1 \mathrm{mg} / \mathrm{ml}$, respectively, when appropriate. E. coli 


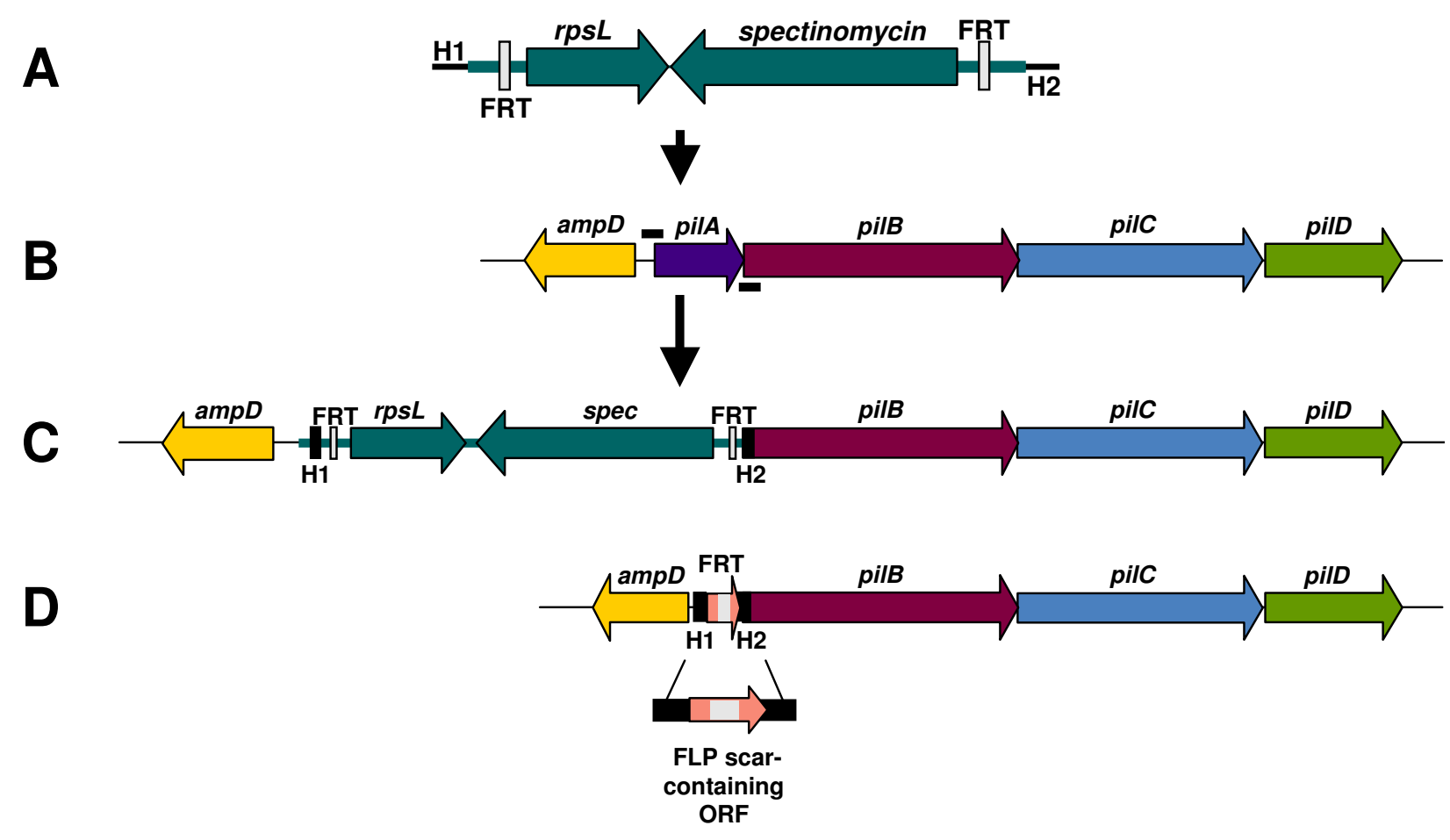

Figure 2

Construction of a non-polar pilA mutant. The PCR amplicon from Figure I is shown in Panel A. The cloned pilABCD region of pRSM2855 is shown in Panel B. The amplicon was electroporated into E. coli DY380(pRSM2855) and the lambda recombinase genes were induced by temperature shock. Spectinomycin-resistant clones were selected. The insert region of plasmid pRSM2857 is shown in Panel C. Plasmid pRSM2857 was linearized and transformed into NTHi strain 2019 rpsL; spectinomycin-resistant clones were isolated. NTHi strain 2019 rpsL $\Delta$ pilA::spec-rps $L_{\mathrm{Ng}}$ was saved, then transformed with pRSM2947 at the permissive temperature; kanamycin resistant clones were isolated. Expression of the FLP recombinase resulted in the loss of the spectinomycin resistance gene-rps $L_{\mathrm{Ng}}$ cassette; growth at $37^{\circ} \mathrm{C}$ resulted in the loss of the plasmid. The pil region of NTHi strain 2019 rpsL $\Delta$ pilA is depicted in Panel D.

strains were grown on LB broth or agar. Growth media were supplemented with spectinomycin, kanamycin, chloramphenicol or ampicillin at $50 \mu \mathrm{g} / \mathrm{ml}, 20 \mu \mathrm{g} / \mathrm{ml}, 30$ $\mu \mathrm{g} / \mathrm{ml}$ or $50 \mathrm{ug} / \mathrm{ml}$, respectively, when appropriate. Strain DY380 was grown at $32{ }^{\circ} \mathrm{C}$. A complete list of strains and plasmids used in this study is provided [see Additional file $1]$.

Construction of a template plasmid containing a cassette with a spectinomycin resistance gene and an $\mathrm{rpsL}$ gene flanked by FRT sites

The plasmid pKD13 has been used as a template plasmid for the construction of a complete set of $E$. coli strains with mutations in each non-essential gene [12]. We modified this vector by replacing the kanamycin resistance gene with a spectinomycin resistance gene and the $r p s L_{\mathrm{Ng}}$ gene. The plasmid pSpecR [20] was digested with EcoRV and the EcoRV fragment containing the spectinomycin resistance gene was cloned into the EcoRV site of pWSK30 [21]. A plasmid with the correct restriction map was saved as pRSM2790. The counter selectable marker, $r p s L_{\mathrm{Ng}^{\prime}}$ was amplified by PCR using genomic DNA purified from $N$. gonorrhoeae strain FA1090 and primers 1 and 2 containing BamHI and NotI sites at the 5 ' end, respectively (Table 2). The amplicon was digested with NotI and BamHI, then cloned into the plasmid pRSM2790 that had been digested with these enzymes. A plasmid with the correct insert was identified and saved as pRSM2830. The kanamycin cassette from pKD13 was eliminated by PCR amplification of a portion of pKD13 using primers 3 and 4 which face outward from inside the FRT sites. The spectinomycin resistance gene-rps $L_{\mathrm{Ng}}$ cassette was isolated from the pRSM2830 by digestion with SacI and XhoI and cloned into the pKD13-derived PCR product. Clones were selected on LB-agar containing spectinomycin. The plasmid from a spectinomycin-resistant clone was characterized by restriction digestion and sequencing, then saved as pRSM2832. 


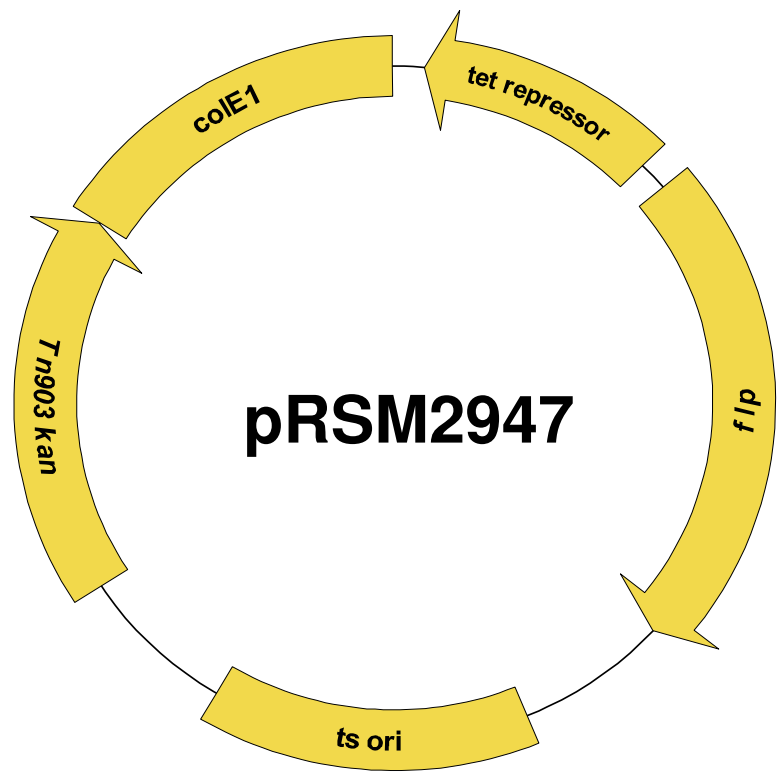

Figure 3

Map of plasmid pRSM2947. The plasmid contains: the FLP recombinase gene under the control of the tet regulatory system; a temperature sensitive replicon suitable for use in NTHi; a ColEl origin that is functional in E. coli and a kanamycin resistance marker.

\section{Amplification of the cassette}

Since lambda recombinase requires less than 50 bp of homology for efficient recombination, PCR primers of approximately $70 \mathrm{nt}$ in length were designed using the strategy of Baba et al [12]. The 5' PCR primer (primer 5) had a $50 \mathrm{nt}$ homology arm (H1) including the sequence upstream of pilA as well as the pilA start codon and the 20 nt sequence 5'-ATTCCGGGGATCCGTCGACC-3' (P1) which is complementary to sequence $5^{\prime}$ of the spectinomycin resistance gene-rpsL cassette (Figure 1). The 3' primer (primer 6) contained the complement of the last $21 \mathrm{nt}$ of the pilA gene including the termination codon and $29 \mathrm{nt}$ downstream (H2) as well as the $20 \mathrm{nt}$ sequence 5'-TGTAGGCTGGAGCTGCTTCG-3' (P2) which is complementary to sequence 3 ' of the spectinomycin resistance gene-rps $L_{\mathrm{Ng}}$ cassette. A PCR amplicon was generated using these primers together with pRSM2832 as the template. Amplification was performed in a $50 \mu \mathrm{l}$ reaction containing 1 U Phusion High Fidelity DNA Polymerase (New England Biolabs), 25 ng pRSM2832 DNA, $0.4 \mu \mathrm{M}$ of each primer, and $200 \mu \mathrm{M}$ dNTPs under the following conditions: $98^{\circ} \mathrm{C}$ for 30 seconds, 30 cycles of $98^{\circ} \mathrm{C}$ for $10 \mathrm{sec}$ onds, $51^{\circ} \mathrm{C}$ for 20 seconds, $72^{\circ} \mathrm{C}$ for 3 minutes, and a final extension of $72^{\circ} \mathrm{C}$ for 10 minutes. The amplicon thus contains the spectinomycin resistance gene-rps $L$ cassette flanked by the homology arms $\mathrm{H} 1$ and $\mathrm{H} 2$.

\section{Construction of a pilA mutant in NTHi strain 2019 rpsL containing the spectinomycin resistance gene-rps $\mathrm{L}_{\mathrm{Ng}}$ cassette}

The pilABCD gene cluster of NTHi strain 2019 as well as 227 bp 5' of the pilA gene was amplified by PCR from genomic DNA purified from NTHi strain 2019 using primers 7 and 8 and cloned into pGEM-T Easy (Promega) (Figure 2B). The nucleotide sequence of the NTHi strain 2019 pilABCD gene cluster is $94 \%$ identical to the gene cluster in strain 86-028NP (Genbank Accession \# CP000057). Plasmid DNA was purified, verified by restriction digestion, and sequenced. A clone with the correct sequence was identified and saved as pRSM2855. Plasmid pRSM2855 was transformed into the E. coli strain DY380 at $32^{\circ} \mathrm{C}$ and clones were selected on LB agar containing ampicillin. Strain DY380 contains a defective lambda prophage with a temperature sensitive repressor

Table I: Transformation of strain 2019 derivatives

\begin{tabular}{|c|c|c|c|}
\hline \multicolumn{4}{|c|}{ Number of transformants/ $\mu \mathrm{g}$ of DNA } \\
\hline \multicolumn{4}{|c|}{ Strains } \\
\hline & $2019 \mathrm{rpsL}$ & $2019 \mathrm{rps} L \Delta p i l A$ & 2019 rpsL $\Delta$ pilA (pRSM2848) \\
\hline Experiment \#I & $5.4 \times 10^{5}$ & ND & $1.3 \times 10^{5}$ \\
\hline Experiment \#2 & $4.8 \times 10^{5}$ & ND & $1.7 \times 10^{5}$ \\
\hline \multicolumn{4}{|c|}{ Strains } \\
\hline & 2019 & 2019 pilA:: $\Omega K m 2$ & 2019 pilA:: $\Omega K m 2$ (pRSM2848) \\
\hline Experiment \#3 & $3.9 \times 10^{3}$ & ND & ND \\
\hline Experiment \#4 & $5.6 \times 10^{3}$ & ND & ND \\
\hline
\end{tabular}

ND is not detected. 
Table 2: Oligonucleotide primers

\begin{tabular}{|c|c|}
\hline Primer & Sequence \\
\hline primer I & GCGGATCCCCGACTGATTGTGAGGGATGTCGG \\
\hline primer 2 & GCGCGGCCGCCCGACTGATTGTGAGGGATGTCGG \\
\hline primer 3 & GCGAGCTCGCATCGCCTTCTATCGCCTTCTTG \\
\hline primer 4 & GCCTCGAGCAGCCCTTGCGCCCTGAGTG \\
\hline primer 5 & СTTTTCACAATGTTGTCGCTAACAAAGGCTTAATAAAAGGAAAATGAATGATTCCGGGGATCCGTCGACC \\
\hline primer 6 & ACGCTGAGTATGAAGTAAAGCATAGCTCGTCATTTTGTGACACTTCTGCATGTAGGCTGGAGCTGCTTCG \\
\hline primer 7 & GCGCGTCGACAACCAATAAGGAAATA \\
\hline primer 8 & CGAGGCAATGGATCAACAGAAG \\
\hline primer 9 & GGGCGTTTATCGAAGTGAGG \\
\hline primer 10 & TCAACCCCTAGCCAAAGAC \\
\hline primer II & CGCGGATCCTGCCGCCTGTTTTTTCCTGCTCATT \\
\hline primer 12 & CTGTTATCCTTAAATCTCGCTTATTAGGTGTGCTTGTATTTCTTGGG \\
\hline primer 13 & CCCAAGAAATACAAGCACACCTAATAAGCGAGATTTAAGGATAACAG \\
\hline primer 14 & CGCGGATCCGCGGCCGCGTGACACGACGATGCTAAA \\
\hline primer 15 & ATATAATGCGGCCGCTACGGTTATCCACAGAATCA \\
\hline primer 16 & ATATAATGCGGCCGCCTCACTGATTAAGCATTGG \\
\hline primer 17 & CGCGGATCCCGATGGGTGGTTAACTCGAC \\
\hline primer 18 & CGCGGATCCACAGGACGGGTG \\
\hline primer 19 & GCACGCGTTCGTCAAATATTACGGATATTAA \\
\hline primer 20 & GCACGCGTTCATTGTGTGACACTTCCG \\
\hline
\end{tabular}

Restriction endonuclease cleavage sites are shown in bold.

[14]. In this strain, the lambda recombinase genes are actively transcribed after temperature shock at $42^{\circ} \mathrm{C}$.

To construct a plasmid containing a marked deletion of the pilA gene, $200 \mathrm{ng}$ of PCR product containing the spectinomycin resistance gene- $r p s L_{\mathrm{Ng}}$ cassette was electroporated into E. coli DY380(pRSM2855) that had been heat shocked at $42^{\circ} \mathrm{C}$ for 15 minutes prior to preparation of electrocompetent cells as described by Lee et al [14]. Clones were then selected at $32^{\circ} \mathrm{C}$ on $\mathrm{LB}$ agar containing spectinomycin. A plasmid containing a deletion of the
pilA gene with an insertion of the cassette was identified and saved as pRSM2857 (Figure 2C).

Plasmid pRSM2857 was digested with NcoI and NsiI to release the insert from the pGEM-T Easy vector backbone, then transformed into NTHi strain 2019 rpsL using the MIV methodology [11]. Clones were selected on chocolate agar supplemented with spectinomycin. Putative mutants were screened for streptomycin sensitivity on chocolate agar containing streptomycin. The genotype of presumptive mutants was further characterized by PCR 
amplification of the genomic region using primers 9 and 10 , followed by sequencing.

\section{Construction of the FLP Recombinase containing plasmid, pRSM2947}

Deletion of the cassette to generate the non-polar mutation in NTHi strain 2019 rpsL requires the activity of the FLP recombinase. We constructed a temperature sensitive plasmid containing the FLP recombinase gene under the control of the tet promoter/repressor system. Briggs and Tatum previously reported the construction of a plasmid with a temperature sensitive replicon suitable for use in members of the Pasteurellaceae family [22]. This plasmid has the same replicon as the plasmid pLS88 [23]. A point mutation of G to A at base 2196 of pLS88 was introduced into a fragment of pLS88 containing the replicon and kanamycin resistance gene using overlap PCR. Briefly, amplicons 1 and 2 corresponding to NT 1715 to 2220 and 2174 to 4093 of pLS88 were generated with primers 11 and 12 or primers 13 and 14, respectively, using pLS88 DNA as template. Amplicon 3 was generated with primers 11 and 14, which both contain BamHI sites, using amplicons 1 and 2 as template. The amplicon was digested with BamHI, and self-ligated. The ligation mixture was transformed into $H$. influenzae strain Rd by electroporation. Plasmid-containing strains were selected by growth at $32^{\circ} \mathrm{C}$ on chocolate agar containing kanamycin. Strains containing the correct plasmid were identified by screening for growth at $32^{\circ} \mathrm{C}$, but absence of growth at $37^{\circ} \mathrm{C}$ on chocolate agar containing kanamycin. A temperature sensitive plasmid was saved as pRSM2865. This intermediate plasmid is $2.3 \mathrm{~Kb}$ in size and contains unique NotI and BamHI sites. The presence of the mutation in pRSM 2865 was confirmed by DNA sequencing. Although pLS88 is stably maintained in E. coli, pRSM2865 could not be maintained in E. coli, even when grown at $32^{\circ} \mathrm{C}$. Thus, for convenience, a fragment of pUC19 containing the ColE1 replicon was amplified with primers 15 and 16; both primers contain a NotI site. The resulting amplicon was digested with Not I, then cloned into NotI-digested pRSM2865. After transformation into E. coli strain DH5 $\alpha$, a plasmid with the correct restriction map was saved as pRSM2866. Using pFT-A [24] as template and primers 17 and 18, which contain BamHI sites, an amplicon was generated which contained the FLP recombinase gene under control of the tet promoter/repressor system flanked by BamHI sites. The amplicon was digested with BamHI and the product ligated to BamHI-digested pRSM2866. The ligation mixture was transformed into DH5 $\alpha$ and clones selected on LB agar containing kanamycin. A plasmid with the correct restriction map was identified and saved as pRSM2947 (Figure 3).

\section{Construction of pilA mutants in NTHi strain 2019 background}

In order to construct an in-frame, non-polar deletion of the cloned pilA gene in NTHi strain 2019 rpsL, plasmid pRSM2947 was transformed by electroporation into NTHi strain $2019 r p s L \Delta$ pilA::spec-rps $L_{\mathrm{Ng}}$ and transformants were selected at $32^{\circ} \mathrm{C}$ on chocolate agar containing kanamycin. Clones were grown at $32^{\circ} \mathrm{C}$ in sBHI broth supplemented with kanamycin until a final absorbance $(600 \mathrm{~nm})$ of 0.30 was reached. The FLP recombinase was then induced with $200 \mathrm{ng}$ of anhydrotetracycline/ $\mathrm{ml}$ for 2 hours, shaking $(180 \mathrm{rpm})$ at $32^{\circ} \mathrm{C}$. Unmarked mutants were then selected by growth at $37^{\circ} \mathrm{C}$ on chocolate agar supplemented with streptomycin. Mutants were then screened for loss of both spectinomycin and kanamycin resistance genes and the genotype was verified by PCR and sequencing (Figure 2D). Although convenient, the streptomycin counterselection is not necessary. After induction of the FLP recombinase using our methodology, the cassette is resolved in approximately $2 \%$ of the clones; thus, it is possible to identify mutants by screening. A detailed protocol for mutant construction in NTHi strains is provided [see Additional file 2].

A polar mutation in the pilA gene of strain 2019 was constructed as described [4]. The mutant is designated 2019

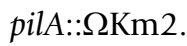

\section{Complementation of the pilA mutation in NTHi strains 2019 rpsL $\triangle$ pilA and 2019 pilA:: $\Omega K m 2$}

The plasmid pPIL1 containing the NTHi pilABCD gene cluster [4] was PCR amplified with primers 19 and 20, which face outward from the 3 ' end of pilA and the 3 'end of pilD. The primers both contain MluI sites on their $5^{\prime}$ ends. The amplicon was digested with MluI, self-ligated, and transformed into $H$. influenzae strain $\mathrm{Rd}$. The resulting plasmid contained the pSPEC1 backbone, the pilA gene, and a small ORF containing the 5' portion of the pilB gene cloned in-frame with the 3 ' end of the pilD gene. A clone with the correct restriction map was sequenced, then saved as pRSM2848. The plasmid pRSM2848 was then transformed into NTHi strains 2019 rpsLApilA and 2019

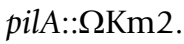

\section{Cloning and insertional inactivation of the cya gene}

We cloned and insertionally inactivated the cya gene. This interrupted gene was used to test the strains for their ability to be transformed. The cya gene from $H$. influenzae strain Rd and approximately $1 \mathrm{~Kb}$ of flanking DNA 5 ' and 3 ' to the gene were amplified and cloned into pGEM-T Easy essentially as described for construction of pRSM2855. A clone with the correct restriction map was saved as pRSM2921. The non-polar kanamycin cassette [9] was cloned into KpnI- and BamHI-digested pRSM2921 as a KpnI to BamHI fragment. After ligation 
and transformation, a plasmid containing the insertionally inactivated cya gene was identified and saved as pRSM2948. The cloned cya gene was also insertionally inactivated by cloning a BamHI fragment containing the chloramphenicol cassette from pUCAEcat into BglIIdigested pRSM2921. As plasmid containing the insertionally inactivated cya gene was saved as pRSM3004.

\section{Determination of transformation efficiency}

Transformation efficiency was determined in strains 2019 rpsL, 2019 rpsLApilA and 2019 rpsLApilA(pRSM2848). DNA from NotI-digested pRSM2948 was incubated with cells treated to induce competence using the modified MIV methodology; transformants were identified on chocolate agar plates containing kanamycin. Similarly, transformation efficiency was determined in strains 2019

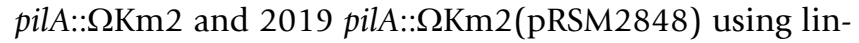
earized pRSM3004 as above, except that transformants were selected on chloamphenicol-containing medium.

\section{Authors' contributions}

ET and RSM designed the strategy and drafted the manuscript. FY constructed pRSM2947. BB cloned and insertionally inactivated the NTHi cya gene. ET was responsible for generation of the template plasmid, construction of the mutants and the transformation experiments. All authors read and approved the final manuscript.

\section{Additional material}

\section{Additional file 1}

Bacterial strains and plasmids. This table contains a complete list of strains and plasmids used in this study.

Click here for file

[http://www.biomedcentral.com/content/supplementary/14712199-9-101-S1.pdf]

\section{Additional file 2}

Protocol for construction of mutants in NTHi. A detailed protocol is presented to aid investigators in the use of this technology.

Click here for file

[http://www.biomedcentral.com/content/supplementary/1471-

2199-9-101-S2.pdf]

\section{Acknowledgements}

This work was supported by NIH grants R0IDC007464 to RSM, ROIDC0039I 5 to Lauren Bakaletz and a subcontract from N0IAI30040 to Michael Apicella. We thank Michael Apicella for the gifts of NTHi strains 2019 and 2019 rpsL.

\section{References}

I. Kilpi T, Herva E, Kaijalainen T, Syrjanen R, Takala AK: Bacteriology of acute otitis media in a cohort of Finnish children followed for the first two years of life. Pediatr Infect Dis J 200I, 20(7):654-662.
2. Murphy TF: Respiratory infections caused by non-typeable Haemophilus influenzae. Curr Opin Infect Dis 2003, 16(2): 129-134.

3. Craig L, Pique ME, Tainer JA: Type IV pilus structure and bacterial pathogenicity. Nat Rev Microbiol 2004, 2(5):363-378.

4. Bakaletz LO, Baker BD, Jurcisek JA, Harrison A, Novotny LA, Bookwalter JE, Mungur R, Munson RS Jr: Demonstration of Type IV pilus expression and a twitching phenotype by Haemophilus influenzae. Infect Immun 2005, 73(3):1635-1643.

5. Jurcisek JA, Bakaletz LO: Biofilms formed by nontypeable Haemophilus influenzae in vivo contain both double-stranded DNA and type IV pilin protein. J Bacteriol 2007, I 89(10):3868-3875.

6. Jurcisek JA, Bookwalter JE, Baker BD, Fernandez S, Novotny LA, Munson RS Jr, Bakaletz LO: The PilA protein of non-typeable Haemophilus influenzae plays a role in biofilm formation, adherence to epithelial cells and colonization of the mammalian upper respiratory tract. Mol Microbiol 2007, 65(5): $1288-1299$.

7. Redfield RJ, Cameron AD, Qian Q, Hinds J, Ali TR, Kroll JS, Langford PR: A novel CRP-dependent regulon controls expression of competence genes in Haemophilus influenzae. J Mol Biol 2005, 347(4):735-747.

8. VanWagoner TM, Whitby PW, Morton DJ, Seale TW, Stull TL: Characterization of three new competence-regulated operons in Haemophilus influenzae. J Bacteriol 2004, I 86( (19):6409-642I .

9. Menard R, Sansonetti PJ, Parsot C: Nonpolar mutagenesis of the ipa genes defines IpaB, IpaC, and IpaD as effectors of Shigella flexneri entry into epithelial cells. J Bacteriol 1993, 175( I 8):5899-5906.

10. Mason KM, Munson RS Jr, Bakaletz LO: A mutation in the sap operon attenuates survival of nontypeable Haemophilus influenzae in a chinchilla model of otitis media. Infect Immun 2005, 73(I):599-608.

II. Poje G, Redfield RJ: Transformation of Haemophilus influenzae. Methods Mol Med 2003, 7I:57-70.

12. Baba T, Ara T, Hasegawa M, Takai Y, Okumura Y, Baba M, Datsenko KA, Tomita M, Wanner BL, Mori H: Construction of Escherichia coli K-I 2 in-frame, single-gene knockout mutants: the Keio collection. Mol Syst Biol 2006, 2:2006.0008.

13. Datsenko KA, Wanner BL: One-step inactivation of chromosomal genes in Escherichia coli K-1 2 using PCR products. Proc Natl Acad Sci USA 2000, 97( I 2):6640-6645.

14. Lee EC, Yu D, Martinez de Velasco J, Tessarollo L, Swing DA, Court DL, Jenkins NA, Copeland NG: A highly efficient Escherichia colibased chromosome engineering system adapted for recombinogenic targeting and subcloning of BAC DNA. Genomics 200I, 73(I):56-65.

15. Copeland NG, Jenkins NA, Court DL: Recombineering: a powerful new tool for mouse functional genomics. Nat Rev Genet 200I, 2(I 0):769-779.

16. Johnston DM, Cannon JG: Construction of mutant strains of Neisseria gonorrhoeae lacking new antibiotic resistance markers using a two gene cassette with positive and negative selection. Gene 1999, 236(1):179-184.

17. Campagnari AA, Gupta MR, Dudas KC, Murphy TF, Apicella MA: Antigenic diversity of lipooligosaccharides of nontypable Haemophilus influenzae. Infect Immun 1987, 55(4):882-887.

18. Johnston JW, Zaleski A, Allen S, Mootz JM, Armbruster D, Gibson BW, Apicella MA, Munson RS Jr: Regulation of sialic acid transport and catabolism in Haemophilus influenzae. Mol Microbiol 2007, 66(I):26-39.

19. Jurcisek J, Greiner L, Watanabe H, Zaleski A, Apicella MA, Bakaletz LO: Role of sialic acid and complex carbohydrate biosynthesis in biofilm formation by nontypeable Haemophilus influenzae in the chinchilla middle ear. Infect Immun 2005, 73(6):3210-3218.

20. Whitby PW, Morton DJ, Stull TL: Construction of antibiotic resistance cassettes with multiple paired restriction sites for insertional mutagenesis of Haemophilus influenzae. FEMS Microbiol Lett 1998, I 58( I):57-60.

21. Wang RF, Kushner SR: Construction of versatile low-copynumber vectors for cloning, sequencing and gene expression in Escherichia coli. Gene 1991, 100:195-199.

22. Briggs RE, Tatum FM: Generation and molecular characterization of new temperature-sensitive plasmids intended for 
genetic engineering of Pasteurellaceae. Appl Environ Microbiol 2005, 7 I (II ):7I87-7I95.

23. Dixon LG, Albritton WL, Willson PJ: An analysis of the complete nucleotide sequence of the Haemophilus ducreyi broad-hostrange plasmid pLS88. Plasmid 1994, 32(2):228-232.

24. Posfai G, Koob MD, Kirkpatrick HA, Blattner FR: Versatile insertion plasmids for targeted genome manipulations in bacteria: isolation, deletion, and rescue of the pathogenicity island LEE of the Escherichia coli O157:H7 genome. J Bacteriol 1997. I 79(13):4426-4428.

25. Hansen EJ, Latimer JL, Thomas SE, Helminen M, Albritton WL, Radolf JD: Use of electroporation to construct isogenic mutants of Haemophilus ducreyi. J Bacteriol I992, I 74( (16):5442-5449.

26. Perez-Casal J, Caparon MG, Scott JR: Mry, a trans-acting positive regulator of the $M$ protein gene of Streptococcus pyogenes with similarity to the receptor proteins of two-component regulatory systems. J Bacteriol I99I, 173(8):2617-2624.

Publish with Bio Med Central and every scientist can read your work free of charge

"BioMed Central will be the most significant development for disseminating the results of biomedical research in our lifetime. "

Sir Paul Nurse, Cancer Research UK

Your research papers will be:

- available free of charge to the entire biomedical community

- peer reviewed and published immediately upon acceptance

- cited in PubMed and archived on PubMed Central

- yours - you keep the copyright 